\title{
Alcohol: A Double-Edged Sword in the Fight Against COVID-19
}

\author{
Sajjad Bahariniya (iD ${ }^{1}$ and Farzan Madadizadeh (iD ${ }^{2,{ }^{*}}$ \\ ${ }^{1}$ Masters Student of Health Services Management, School of Public Health, Shahid Sadoughi University of Medical Sciences, Yazd, Iran \\ ${ }^{2}$ Center for Healthcare Data Modeling, Departments of Biostatistics and Epidemiology, School of Public Health, Shahid Sadoughi University of Medical Sciences, Yazd, Iran \\ "Corresponding author: Center for Healthcare Data Modeling, Departments of Biostatistics and Epidemiology, School of Public Health, Shahid Sadoughi University of Medical \\ Sciences, Yazd, Iran. Email: madadizadehfarzan@gmail.com
}

Received 2021 February 03; Revised 2021 April 16; Accepted 2021 April 28.

Keywords: Alcohol, COVID-19, Sanitizer

\section{Dear Editor,}

Currently, most countries are facing the coronavirus disease 2019 (COVID-19) pandemic worldwide. The social media and news websites spread information about selfprotecting with alcohol, some of which are mainly beneficial to the individuals, and some are misinformation (1).

Alcohols bind with other atoms to create secondary alcohols. These secondary alcohols are the three types of alcohol, including ethyl alcohol (ethanol), methyl alcohol (methanol), and isopropanol (2). Among these alcohol types, ethanol is safe for drinking, and other poisonous types should only be used for cleaning. Ethanol abuse and addiction has damaging side effects overtime on human organs such as the liver, brain, and immune system, and it can even lead to disability and death (3).

Although consuming alcohol is legally prohibited in Iran due to Islamic rules, a study conducted in 2016 on mental health showed a 5.7\% prevalence of alcohol consumption in the country (2). During the COVID-19 outbreak, some people and social media shared questionable and false advice on protecting from COVID-19 infection, one of which was drinking alcohol (4). The idea behind this false advice was that since alcohol is a disinfectant, so it can also disinfect body organs and strengthen immune system. In some cases, it was falsely claimed that the advice came from medical universities.

As a result of the false news that drinking alcoholic drinks, especially vodka, could fight and reduce the risk of getting COVID-19, some Iranians started drinking it. So, according to the Iranian forensic medicine report, at least 800 Iranian people died after drinking poisoning alcohols from February 19 to April 25, 2020. Also, some people mistakenly sprayed alcohol on their masks and bodies (5). Despite the significant role of alcohol in disinfecting surfaces and objects, its continued spraying on the hands and masks could damage the skin and eyes and increase the risk of respiratory disease. Moreover, its absorption through the skin could penetrate the nervous system, which can disrupt the nerve function and body's logical response, such as post-drug disorder and addiction (6).

There is no scientific evidence that alcohol consumption can help in reducing and preventing COVID-19 infection (7). In this regard, the Centers for Disease Control and Prevention (CDC) and the World Health Organization (WHO) did not mention any advantage for drinking alcohol, and they only recommended topical use of alcohol as a hand sanitizer along with 20 seconds of handwashing with soap and water. Hence, no official organization has suggested drinking alcohol and spraying it on the body and mask.

Some studies suggest that alcohol may weaken the immune system and increase the risk of viral and bacterial infections $(6,8)$. Therefore, it is necessary for the relevant authorities to inform people about the excessive use and consumption of alcohol to avoid its consequences and dangers. An alternative solution is to use alcohol-free sanitizers since several studies in recent years (9-11) recommended the use of non-alcoholic sanitizers, in which case their side effects would be far less than those of alcoholbased sanitizers.

\section{Footnotes}

Authors' Contribution: S.B. and F.M., conceived the presented idea; S.B., wrote the manuscript with support from F.M., S.B., and F.M. All authors read the manuscript and confirmed the final version.

Conflict of Interests: The author had no conflict of interest.

Funding/Support: This study received no funding. 


\section{References}

1. Taheri Soodejani M, Tabatabaei SM, Dehghani A, McFarland W, Sharifi $\mathrm{H}$. Impact of mass screening on the number of confirmed cases, recovered cases, and deaths due to COVID-19 in Iran: An interrupted time series analysis. Arch Iran Med. 2020;23(11):776-81. doi: 10.34172/aim.2020.103. [PubMed: 33220696].

2. Nguyen TVN, Paugam L, Rabiller P, Rabiller-Baudry M. Study of transfer of alcohol (methanol, ethanol, isopropanol) during nanofiltration in water/alcohol mixtures. J Membr Sci. 2020;601:117907. doi: 10.1016/j.memsci.2020.117907.

3. World Health Organization. Coronavirus disease (COVID-19) advice for the public: Mythbusters. Geneva, Switzerland: World Health Organization; 2021. Available from: https://www.who.int/emergencies/ diseases/novel-coronavirus-2019/advice-for-public/myth-busters.

4. Chick I. Alcohol and COVID-19. Alcohol Alcohol. 2020;55(4):341-2. doi: 10.1093/alcalc/agaa039. [PubMed: 32400878]. [PubMed Central: PMC7239251].

5. Aghababaeian H, Hamdanieh L, Ostadtaghizadeh A. Alcohol intake in an attempt to fight COVID-19: A medical myth in Iran. Alcohol. 2020;88:29-32. doi: 10.1016/j.alcohol.2020.07.006. [PubMed: 32693023]. [PubMed Central: PMC7368655].

6. Clay JM, Parker MO. Alcohol use and misuse during the COVID19 pandemic: A potential public health crisis? Lancet Public
Health.2020;5(5). e259. doi: 10.1016/S2468-2667(20)30088-8. [PubMed: 32277874]. [PubMed Central: PMC7195126].

7. Rehm J, Kilian C, Ferreira-Borges C, Jernigan D, Monteiro M, Parry $\mathrm{CDH}$, et al. Alcohol use in times of the COVID 19: Implications for monitoring and policy. Drug Alcohol Rev. 2020;39(4):301-4. doi 10.1111/dar.13074. [PubMed: 32358884]. [PubMed Central: PMC7267161].

8. Chegeni M, Kamel Khodabandeh A, Karamouzian M, Shokoohi M, Abedi L, Khalili M, et al. Alcohol consumption in Iran: A systematic review and meta-analysis of the literature. Drug Alcohol Rev. 2020;39(5):525-38. doi: 10.1111/dar.13093. [PubMed: 32441436].

9. Ogilvie BH, Solis-Leal A, Lopez JB, Poole BD, Robison RA, Berges BK. Alcohol-free hand sanitizer and other quaternary ammonium disinfectants quickly and effectively inactivate SARS-CoV-2. I Hosp Infect. 2021;108:142-5. doi: 10.1016/j.jhin.2020.11.023. [PubMed: 33259880]. [PubMed Central: PMC7700010].

10. Dyer DL, Shinder A, Shinder F. Alcohol-free instant hand sanitizer reduces elementary school illness absenteeism. Fam Med. 2000;32(9):633-8. [PubMed: 11039151].

11. Jing JLJ, Pei Yi T, Bose RJC, McCarthy JR, Tharmalingam N, Madheswaran T. Hand sanitizers: A review on formulation aspects, ad verse effects, and regulations. Int JEnviron Res Public Health. 2020;17(9) doi: 10.3390/ijerph17093326. [PubMed: 32403261]. [PubMed Central: PMC7246736]. 